\title{
Design of Contactless Gesture-based Rhythm Action Game Interface for Smart Mobile Devices
}

\author{
Da Young Ju \\ Yonsei Institute of Convergence Technology, Yonsei University, Incheon, 406-840
}

\begin{abstract}
Objective: The aim of this study is to propose the contactless gesture-based interface on smart mobile devices for especially rhythm action games. Background: Most existing approaches about interactions of smart mobile games are tab on the touch screen. However that way is such undesirable for someone or for sometimes, because of the disabled person, or the inconvenience that users need to touch/tab specific devices. Moreover more importantly, new interaction can derive new possibilities from stranded game genre. Method: In this paper, I present a smart mobile game with contactless gesture-based interaction and the interfaces using computer vision technology. Discovering the gestures which are easy to recognize and research of interaction system that fits to game on smart mobile device are conducted as previous studies. A combination between augmented reality technique and contactless gesture interaction is also tried. Results: The rhythm game allows a user to interact with smart mobile devices using hand gestures, without touching or tabbing the screen. Moreover users can feel fun in the game as other games. Conclusion: Evaluation results show that users make low failure numbers, and the game is able to recognize gestures with quite high precision in real time. Therefore the contactless gesture-based interaction has potentials to smart mobile game. Application: The results are applied to the commercial game application.
\end{abstract}

Keywords: Game, Gesture recognition, Contactless interaction, Smart mobile device, User interfaces

\section{Introduction}

모바일폰(mobile phone) 과 태블렛 PC(tablet PC) 와 같은 새로운 스마트 모바일 디바이스(smart mobile device)가 개발되어 상용화된 이후 이전에 비해 보다 더 직관적인 사용 자 환경-유저 인터페이스(user interface)에 대한 요구가 필수적으로 생겨났다. 그리고 그 중 한 가지가 "제스처 인식 (gesture recognition)" 방식을 적용한 인터페이스이다.

제스처 인식방식을 통한 디바이스와의 인터랙션 (interaction)은 다른 상호작용에 비해 학습기간이 짧고 새 로운 사용자 환경에 적응하는 것이 쉽기 때문에 그 수요가 급속도로 증가하고 있다. 이 중 "비전 기반(vision-based)"
이나 "센서 기반(sensor-based)" 인터랙션의 경우 디바이 스와의 접촉 없이 카메라를 이용한 입력 영상의 분석이나 센서의 반응을 통해 사용자의 제스처를 인식할 수 있으므 로 대상 디바이스와의 정밀한 인터랙션이 어려운 노약자나 장애우를 위한 사용자 환경으로 환영 받고 있다. 또한 신 체 동작을 사용한다는 본능적인 사용자 환경 (natural user interface)으로서의 가치와 운동을 겸할 수 있다는 점, 그리 고 이전의 인터랙션에 비해 색다른 재미요소를 제공할 수 있 다는 점에서도 의미를 가진다.

본 연구에서는 "비전 기반"으로 비접촉(contactless) 제스 처 기반 스마트 모바일 디바이스 용 리듬액션게임(rhythm action game) 과 이를 위한 사용자 환경을 제안한다. 연구에 서 제안하는 비접촉 제스처 인식 기반 리듬액션게임은 스마

Corresponding Author: Da Young Ju. Yonsei Institute of Convergence Technology, Yonsei University, Incheon, 406-840.

Phone: +82-32-749-5848, E-mail: dyju@yonsei.ac.kr

Copyright@2012 by Ergonomics Society of Korea(pISSN:1229-1684 eISSN:2093-8462). All right reserved.

(c) This is an open-access article distributed under the terms of the Creative Commons Attribution Non-Commercial License(http://creativecommons.org/licenses/by-nc/3.0/), which permits unrestricted non-commercial use, distribution, and reproduction in any medium, provided the original work is properly cited. http://www.esk.or.kr 
트 모바일 디바이스에서는 세계적으로 시도된 예를 찾기 힘 들며, 본 논문에서는 제안한 게임의 개발 사례와 함께 이 모 바일 게임에 최적화된 유저 인터페이스의 디자인 과정을 설 명한다.

대상으로 하는 리듬액션게임의 경우 다른 스마트 모바일 디바이스 용 어플리케이션들 혹은 콘텐츠들에 비해 많은 입 력 값과 좀 더 빠른 실시간 인터랙션을 요구하며 정확한 상 호작용-게임 플레이 상의 입력과 응답-이 이루어져야만 한 다. 제스처의 인식, 특히 비접촉 제스처의 인식은 많은 연산 량으로 인해 모바일폰에서 직접 처리하는 것이 쉽지 않다. 또한 스마트 디바이스에서의 비접촉 제스처 인식 게임의 개 발에는 기술적인 고려 이전에 실시간으로 사용자 입력을 적 용하는데 필요한 제스처의 결정과 인터페이스의 디자인이 중요한 요소로 작용하였다.

\section{Previous Works}

리듬게임 혹은 리듬액션게임 장르는 역사 속에 많은 발전 을 거듭해 왔다. 장르적 특성 상, 리듬에 맞추어 자연스럽게 신체를 움직이게 되므로 초기부터 신체를 사용하는 형태로 개발되었다. Figure 1과 Table 1에서 볼 수 있듯이 게임 방 식 중에는 실제 악기형태를 차용한 인터페이스나 패드 위에 서 뛰면서 리듬을 맞추는 형태의 발판 인터페이스 등이 제공 되기도 하였으며, 초기에는 상당부분 아케이드 게임형태로 개발되었으나, 점차 가정용 게임기의 형태로 축소되고 단순 화 되어 보급되었다.

Table 1. Play types and interfaces of rhythm games

\begin{tabular}{c|c|c}
\hline Games & Play & UI \\
\hline $\begin{array}{c}\text { Band master } \\
\text { EZ2DJ }\end{array}$ & Button input & Buttons \\
\hline $\begin{array}{c}\text { Beat mania } \\
\text { Drum mania }\end{array}$ & Play instrument & Instruments \\
\hline $\begin{array}{c}\text { DDR } \\
\text { PUMP }\end{array}$ & Foot pad input & Foot pads \\
\hline On smart devices & Touch screen & GUI on screen \\
\hline
\end{tabular}

그러나 최근 몇 년 간 스마트폰과 같은 스마트 모바일 기기의 상용화 이후에는 초기의 아케이드 및 악기 기반의 형태는 많이 사라지고 많은 숫자의 리듬게임이 터치 기반의 스마트 디바이스용 게임으로 제공되고 있다.

게임 인터페이스에 대한 연구는 오랫동안 진행되어 왔으

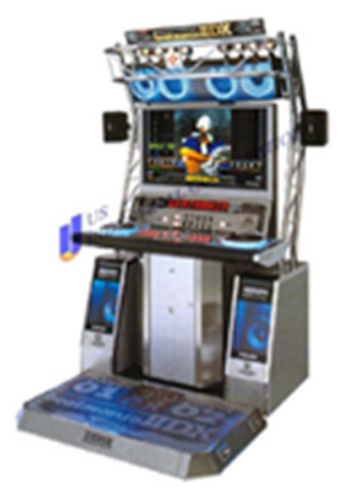

(a)

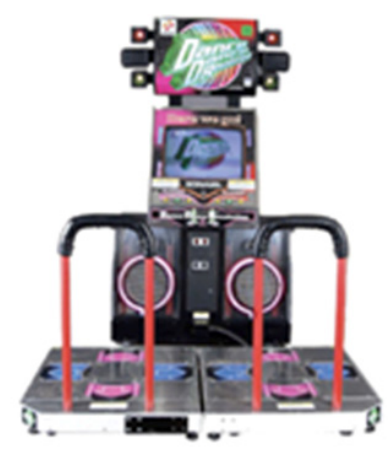

(b)

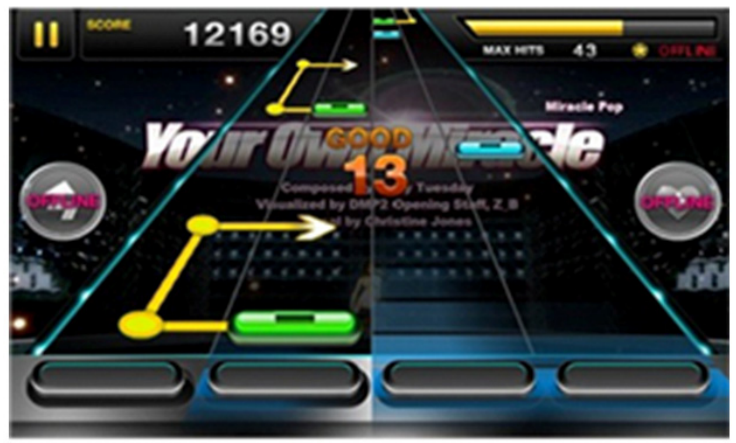

(c)
Figure 1. Rhythm action games: (a) Beat mania(instrument UI), (b) DDR(foot pad UI), (c) Tab sonic(touch UI)

나, 그 중 리듬액션게임 인터페이스에 관계된 연구들 중 일 부를 다음에 정리하였다. Blain(2005)은 12가지 이상의 리듬액션게임 인터페이스 및 콘트롤러들을 분석하여 새로 운 비디오 게임용 리듬액션게임 인터페이스를 제안하고자 하였다.

Yuk(2009)은 스마트 모바일 디바이스 상의 핑거 터치 인터랙션들을 정의하고 기능에 적합한 인터페이스를 제안하 였다. Hoysniemi(2006)는 신체 제스처를 사용하는 게임들 에 대해 방대한 연구 결과를 학위논문으로 발표하였고, Park and Kihl(2011)은 스마트 기기에서 상용화된 리듬액션게임 을 대상으로 어떠한 인터페이스를 적용하고 있는지를 조사 및 분석하였다.

스마트 모바일 디바이스에서 실제 게임을 개발하기 위한 필수 기술인 제스처 인식 분야에는 많은 연구 결과들이 존 재한다. Pavlovic, Sharma, and Huang (1997) 과 Mitra and Acharya (2007)는 제스처 기반 인터페이스가 사용자와 컴 퓨터와의 상호작용에서 보다 더 직관적인 명령 방식을 제 공한다고 하였고, Wilson and Shafer (2003) 과 Liu, Zhong, Wickramasuriya, and Vasudevan(2009)의 모션 기반 인 
식 시스템에서 사용자는 모바일 디바이스를 잡지 않고는 제스처를 취할 수 없으며, Westerman and Elias(2006)과 Wobbrock, Wilson, and $\operatorname{Li}(2007)$ 의 터치 기반 시스템은 3 차원적인 지시는 적용할 수 없었다. 앞의 두 가지 시스템의 경우, 유저와 디바이스 간의 접촉을 필수로 요구하는데 반 해, Mitra and Acharya(2007) 와 Yang, Ahuja, and Tabb (2002)의 비전 기반 시스템은 카메라와 비전 기법의 사용 으로 디바이스와의 접촉 없이 좀 더 직관적인 제스처가 가 능하도록 돕는다.

게임에 비접촉 제스처 입력 방식을 적용한 예로 Park, Kim, Park, and Lee(2005)은 카메라 2대를 이용하여 복싱 글러브의 위치를 알아내고 추적하여 게임에 적용하였으며, He, Park, Kang, and Jung(2011)은 3D 깊이 (3D depth) 카메라를 이용하여, 사용자의 신체 제스처를 인식하는데 이 는 Microsoft사의 Kinect와 유사한 형태이다. Lee, Oh, and Lee (2011)는 모바일폰 상의 게임에서 사용자 제스처 입력 을 인식하여 상호작용을 구현하였으나, 실제 영상 입력과 연 산은 별도의 카메라와 컴퓨터를 사용하고, 모바일폰과 통신 하는 형태로 이루어졌다. Mistry and Zhang(2011)은 손 제 스처를 인식하여 $3 \mathrm{D}$ 자동차 경주(racing) 게임의 조작을 $\mathrm{PC}$ 상에서 가능하게 하였다.

\section{Contactless Gesture Interaction}

앞에서 소개한 이전의 관련 연구들과는 달리, 본 논문에 서는 스마트 모바일 디바이스 상에서의 비접촉 제스처 인터 랙션이 가능한 리듬액션게임을 구현하고 그 인터페이스를 제안하고자 한다. 스마트 디바이스 상에서의 비접촉 제스처 인터랙션은 스마트폰을 흔들거나 기울이는 것과 같은 제스 처 인터랙션, 탭(tab)하는 터치 제스처 인터랙션과 달리 접 촉이 전혀 없는 상태에서 사용자와 기기 간의 상호작용이 가능하도록 해야 한다. 현재 상용화된 스마트 기기에서의 이 러한 비접촉 인터랙션은 손을 좌우로 흔드는(swipe) 제스처 인식 기술만이 상용화가 가능할 정도로 개발되어 적용되고 있다. 그러므로 본 연구에서는 비접촉 제스처 기반 리듬액션 게임의 구현을 위한 인터페이스를 디자인함과 동시에 실시 간 핸드 제스처 인식 기술 또한 구현하였다. 실험을 위한 게 임 장르 중 리듬액션게임을 선정한 이유는 입력 값인 제스처 의 인식 정도를 가장 직관적으로 파악할 수 있고 동시에 장 르가 본래 신체를 이용함으로써 비접촉 제스처 인터랙션을 적용하기에 가장 적합한 게임의 분야라고 판단하였기 때문 이다.

\subsection{Designing AR user interface}

Figure 1의 (c)에서 볼 수 있듯이, 스마트 디바이스 상의 리듬액션게임의 인터페이스는 손가락으로 탭하기 쉬운 크기 와 형태의 그래픽으로 표현되는 음원의 노트(note)를 빠르 고 정확하게 터치하는 형태로 디자인되어 있다. 그러나 비접 촉 인터랙션을 통해 게임을 진행하고자 하면, 사용자는 직접 터치하는 것과 달리 정확한 제스처를 취했는지 여부를 확인 할 수 없기 때문에 게임의 진행이 불가능하였으며 재미도 느 낄 수 없었다.

그래서 본 연구에서는 사용자가 게임 내에서 스스로의 제 스처를 확인하며 게임을 진행하도록 하기 위해 일종의 증강 현실(augmented reality) 사용자 환경을 구성하였고, 나머 지 그래픽 인터페이스(GUI)는 점수와 노트 일치 확인, 배경 등의 요소로 적용하였다. 완성된 게임의 캡처화면인 Figure 4 에서 확인할 수 있다.

\subsection{Adapted hand gestures}

본 연구에서 게임에 적용한 핸드 제스처의 종류는 비접촉 제스처 인식 기법 알고리즘에서 실시간으로 인식이 가능한 수준의 제스처만을 선택해야 했으므로 실험 초기의 설계에 비해 그 다양성은 많이 줄어들었다. Figure 2 의 왼쪽 이미지 는 사용자가 한 손에 스마트폰을 든 채로 다른 한 손으로 취 할 수 있는 핸드 제스처의 예이다. Figure 2의 오른쪽 이미 지는 이러한 실제 핸드 제스처를 게임에서 지시할 때에 보 여주는 핸드 제스처의 지시용 그래픽 인터페이스의 일부이 다. 기존의 리듬액션게임은 눈에 보이는 노트를 터치하면 되지만, 제스처 인식으로 게임을 구성하게 되면 기존 게임 방식대로 제공되는 노트와 제스처의 일치를 확인하기 어려 우므로 Table 2과 Table 3에서 보듯이 노트에 내부적으로 특정 제스처를 기록해 두고, 사용자가 해당 시점에 동일 제 스처를 취하면 점수를 획득하는 형태로 기존의 리듬액션게 임을 새롭게 디자인하게 되었다.

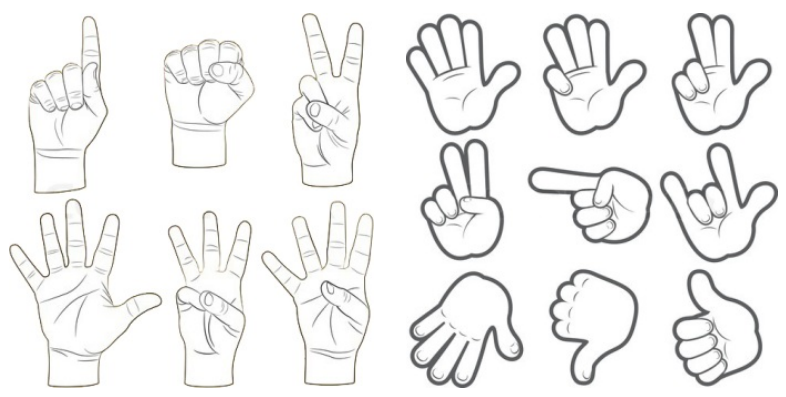

Figure 2. Left: Original hand gestures, Right: GUI on game 
초기 실험은 손등 방향과 손바닥 방향 양쪽으로 각각 6가 지의 총 12 가지 제스처에 좌우 흔들기(swipe)까지를 핸드 제스처로 적용하였으나, 손 바닥 방향에 비해 손등 방향의 동작이 사용자가 게임플레이 중에 제스처를 취하기가 좀 더 용이하고 인식 결과도 더 좋게 나타나 최종으로 손등 방향 의 가위, 바위, 보 동작과 좌우 흔드는 동작까지 포함한 총 4 가지로 결정되었다.

Figure 3는 일반적인 리듬게임의 진행순서로 본 연구에서 비접촉 제스처 인터랙션은 전 과정이 아닌, 6 번째 단계에 있 는 실제 플레이 상에서만 적용되었으며 나머지 단계에서는 일반적인 터치 방식을 사용하여 게임을 구성하였다.

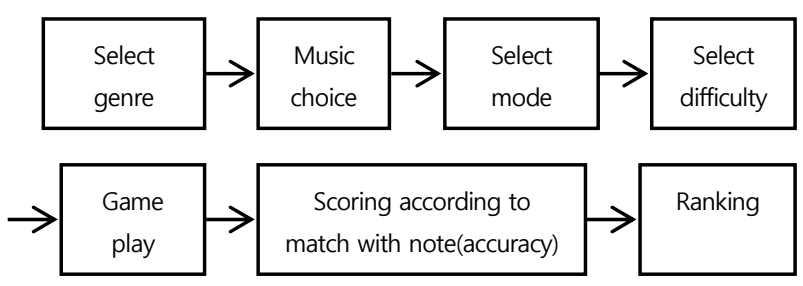

Figure 3. Process of rhythm action game

\subsection{Design of fun}

게임은 각각의 게임의 성격에 따라 여러 가지 기능을 가지 고 있지만, 무엇보다 중요한 기능은 사용자에게 재미를 느끼 게 한다는 점이다. 그러므로 본 연구에서 재미를 설계하는 부분은 중요한 연구임과 동시에 비접촉 제스처 인터랙션을 스마트 기기상의 게임에 적용해야만 하는가의 당위성에 대 한 실험이기도 하였다.

리듬액션게임의 재미는 주로 노트가 어떠한 타이밍에 어 떠한 효과로 등장하는가 이므로, 이는 곧 제안한 4 가지 핸드 제스처를 노트와 어떻게 배치해야 하는가와 같은 문제이다. 여기에서는 주요 스마트폰 리듬게임의 인터페이스를 분석한 Park and Kihl(2011)의 입력 인터랙션 유형 분석과 조작 인터페이스 요소 분석 결과를 참고하여 다음의 Table 2 와 같이 제스처를 적용하였다. 각각의 분류는 사용자 관찰 비디 오를 통해 관찰 및 분석하였을 때 가장 자연스러운 제스처를

Table 2. Proposed gesture interaction

\begin{tabular}{c|c|c}
\hline Function & \multicolumn{2}{|c}{ Gesture } \\
\hline Basic action & Paper & Rock \\
\hline Active action & Scissor & Swipe \\
\hline Convergence & \multicolumn{2}{|c}{ Continuing two or three gestures } \\
\hline
\end{tabular}

선택하였으나, 인식률의 한계로 복잡한 인터랙션은 적용할 수 없어 단순한 형태를 가진다.

\subsection{Limitation of interaction}

본 연구에서 가정하는 스마트 모바일 디바이스와 사용자 의 인터랙션은 왼손으로 디바이스를 잡거나, 혹은 거치대에 디바이스를 고정한 뒤, 오른손으로 제스처를 취한다는 것이 다. 오른손으로 고정하고 왼손으로 제스처를 취하는 경우에 대해서는 실험하지 않았으며, 거치대가 아닌 손으로 고정했 을 때에도 흔들림이 없다는 가정을 하므로 한계를 가진다.

사용자에 따라 각도의 문제로 입력된 제스처 영상에 왜곡 이 일어나거나, 배경의 색상에 영항을 받을 수도 있다. 이러 한 연구 상의 가정과 한계에 대해서는 비접촉 제스처 인터랙 션을 스마트 모바일 디바이스에서 더욱 강건하게 구현하기 위해 차후 추가 연구를 통해 극복하여야 하겠다.

\section{Implementation}

본 연구에서는 스마트 모바일폰 중의 하나인 Apple iphone4를 실험 디바이스로 사용하였다. 스마트 디바이스 용 어플리케이션 중 접촉 및 비접촉 제스처를 사용하는 게임 의 입력 방식들의 예는 Table 3 에서 확인할 수 있다. 기존의 게임들 중 비접촉 제스처 인식방법을 사용한 Input method 2에 해당하는 게임들은 낚시, 볼링, 주사위 놀이, 윶놀이 등 과 같이 모바일폰을 기울이거나 흔드는 제스처를 통한 인터 랙션을 게임에 적용하였다.

Table 3. Examples of input methods of games for smart mobile device

\begin{tabular}{c|c|c|c}
\hline $\begin{array}{c}\text { Input method 1: } \\
\text { touch on the screen }\end{array}$ & \multicolumn{2}{|c|}{$\begin{array}{c}\text { Input method 2: } \\
\text { motion of device }\end{array}$} & $\begin{array}{c}\text { Input method 3: } \\
\text { contactless recognition }\end{array}$ \\
\cline { 1 - 3 } Tab & Snap & Tilt & \multirow{2}{*}{$\begin{array}{c}\text { Proposed hand } \\
\text { gesture recognition }\end{array}$} \\
\cline { 1 - 2 } Long-tab & Bounce & Tip & \\
\hline Slash & Rotate & Shake & \\
\hline
\end{tabular}

\subsection{Proposed hand gesture interaction}

제안하는 방법인 비접촉 비전 기반 제스처 인식의 구현 을 위해 본 연구에서는 패턴 인식에 광범위하게 사용되는 $\mathrm{K}$-nearest neighbor $(\mathrm{KNN})$ 알고리즘을 사용한다. 실험을 위한 입력 영상은 별도의 카메라 없이 iPhone4에 기본 장착 
된 카메라를 이용하며, 이미지센서는 500만 화소이고, 영상 은 960*640 pixels 크기로 얻을 수 있었다. 단, 전면 카메 라의 경우 해상도가 떨어진다. 인식과정은 입력 영상의 전처 리, 벡터화, 그리고 분류의 크게 세 단계로 구성되며, Mistry and Zhang(2011)의 연구를 참고한다.

제스처 인식에 사용된 $\mathrm{KNN}(k$-nearest neighbor) 알고 리즘은 이미 가지고 있는 데이터를 기준으로 새로운 데이터 를 분류하는 방법으로, $k$ 는 범위를 의미하며, 해당 범위 안 에서 가까운 이웃 데이터를 조사하여 후보 그룹에서 유의미 한 그룹으로 분류해 나가는 것이다. 그러나 실험의 정밀도를 높이기 위해 선택된 그룹에서 더 중요한 데이터에 가중치를 더하는 Weighted $\mathrm{KNN}$ 알고리즘을 선택하며, WKNN은 거 리를 계산한 뒤, 크기 별로 정렬 후 가까운 값을 구해 가중 평균을 구하게 된다. 그러므로 본 논문에서는 후보 점 $X q$ 의 거리에 따른 각각의 $k$ 이웃의 기여도에 가중치 $W i$ 를 부 여한다.

$$
F\left(X_{q}\right)=\operatorname{argmax} \sum_{i-1}^{k} W i^{*} \delta\left(v, f\left(X_{i}\right)\right)
$$

$X q$ 은 테스트 제스처 영상이고, $V$ 은 트레이닝 세트의 벡 터, $\delta\left(v, f\left(X_{i}\right)\right.$ 은 테스트 후보군과 각 $\mathrm{KNN}$ 클래스 사이의 거리이며, $X_{i}$ 는 각각의 $\mathrm{KNN}$ 을 의미한다. Argmax는 수학 에서 argument of maximum를 의미하며, 주어진 값이 최 대값에 이르는 미지의 값을 가리키는 규칙이다.

\section{Results}

\subsection{Game application}

리듬액션게임이란 음원에 따른 리듬에 맞춰 등장하는 노 트에 일치하도록 실시간으로 입력하는 게임의 형태로 정확 한 위치와 타이밍에 맞게 입력하는 것이 중요하다. 본 연구 에서는 스마트 모바일 디바이스의 특성상 연산속도의 한계 가 있을 수 있으므로, 상대적으로 느린 음원을 사용하였으며, 음원은 이미 출시된 상업용 음원을 연구를 위해 자체 수정하 여 실험하였다.

Figure 4는 구현한 게임의 캡처 영상이다. 실험에 참여한 대상자는 서울과 경기지역에 거주하는 성인으로 1차에 20 40세 사이의 남, 여 10명, 2 차로 20 40세 사이의 남, 여 50 명이며 모두 게임에서 지시하는 그래픽적인 표현에 따라 직관적으로 제스처 인터랙션을 취할 수 있었고, 스마트폰 게임을 이전에 접해본 실험자와 그렇지 않은 실험자의 비율 은 50:50이었다.
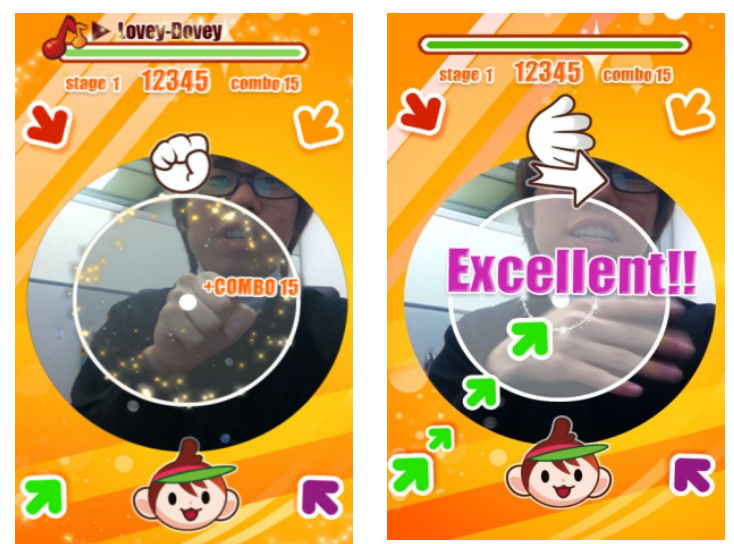

Figure 4. A rhythm game screenshot: Left is ambiguous expression, Right is smile expression

\subsection{Evaluation}

실험은 고정된 디바이스, 검정색 상의는 동일하였으나, 1 차와 2 차 실험에는 차이가 있다. Table 4 의 1 차 실험은 사 용자의 게임 내 제스처 성공률을 평가하기 위하여 3 가지 핸 드 제스처를 2 번씩 반복(총 6차례) 테스트 하였고, 그 결과 로 실험 대상자들이 비교적 높은 인식률을 보였으므로, 인터 랙션의 한 방법으로 비접촉 제스처는 직관적이고 새로운 형 태라는 결론을 얻었다. 이 실험에서의 목표는 기존의 모바일 폰 게임에서나 리듬액션게임에서 시도하지 않았던 비접촉 제스처 인터페이스를 사용자들이 아무런 정보 없이 접했을 때, 직관적으로 즉시 적응하고 이해할 수 있는가라는 문제였 으나 실험자 모두 사전 튜토리얼 없이 게임을 즐길 수 있어 새로운 게임 인터페이스로의 가능성을 증명하였다. 상대적으 로 낮은 인식률을 보인 "가위(Scissors)" 형태의 제스처는 제스처 인식 연구 분야에서 인식이 어려운 제스처에 속하며, 본 연구에서와 같이 낮은 품질의 영상으로는 좋은 인식 결과 를 얻기 힘들다.

Table 4. A success ratio of game playing by 10 users

\begin{tabular}{c|c|c|c}
\hline & Scissors & Rock & Paper \\
\hline $\begin{array}{c}\text { Success numbers } \\
\text { by } 10 \text { testers }\end{array}$ & 3 & 14 & 11 \\
\hline Ratio & $15 \%$ & $70 \%$ & $55 \%$ \\
\hline
\end{tabular}

2 차 실험에서는 1 차와 다른 실험군을 대상으로 하며, 실 험의 목적은 구현된 비접촉 제스처 인터페이스를 가진 스마 트폰 리듬액션게임을 과연 사용자들이 게임으로서 즐길 수 있는지를 알아보는 것이다. "즐긴다"는 추상적인 개념을 분 
석하기 위해 사용한 방법은 게임을 플레이하는 사용자를 관 찰하여 웃는 표정의 회수를 세어 노트의 등장-제스처 인터 랙션이 일어나는 시점, 30회-에 대비한 평균을 측정하였으 며, 결과는 Table 5에서 볼 수 있다.

Table 5. Fun ratio of 50 users

\begin{tabular}{l|c|c|c}
\hline & Smile & Ambiguous & Non smile \\
\hline 25 Gamers & $35 \%$ & $31 \%$ & $34 \%$ \\
\hline 25 Non gamers & $52 \%$ & $34 \%$ & $16 \%$ \\
\hline
\end{tabular}

"즐긴다"는 추상적인 개념의 사용자의 만족도를 평가하기 란 쉬운 일이 아니며 기준을 정하기 매우 어렵다. 본 연구에 서는 결과 분석의 신뢰도를 높이기 위해 이러한 추상적인 개념의 평가를 위한 기준을 실험 후 설문이 아닌 방법으로 매우 엄격하게 지키고자 하였다. 웃는 표정의 기준은 "확실 히 웃는 표정인 경우"를 "즐긴다"로 하고, "전혀 웃지 않는 표정"을 "즐기지 않는다"로 하여 약간 웃거나 미소 짓는 정 도 및 흥미로운 표정 등을 모두 "규정되지 않은 표정"으로 분류하여 보수적인 기준에 따라 높지 않은 만족도를 얻었다. 또한 게임은 즐기고 있으나 집중하는 표정을 짓는 등, 사용 자마다의 개인적 표정 특성이 웃는 표정 없이 게임을 즐기 는 경우를 만들기도 하여, 낮은 결과에 반영되었다. 그러나 모든 실험 대상자들에게 실험 직후 "즐거웠는지"를 묻는 질 문에는 참가자 전원이 "재미있었다"나 "즐거웠다", 혹은 "흥 미로웠다"라는 긍정에 가까운 답변을 함으로 게임이라는 콘 텐츠의 새로운 인터페이스로서의 비접촉 제스처 인터랙션의 가능성을 보여주었다. 마지막으로 게임 시스템 상에서 제스 처를 인식하는 데에는 제스처에 따라, 그리고 상황에 따라 차이가 있었음을 밝힌다.

\section{Conclusion}

본 논문에서는 사용자가 스마트 모바일 디바이스와 핸드 제스처(hand-gesture)을 통하여 인터랙션하는 스마트 모 바일 디바이스 용 비접촉 제스처 인식 리듬액션게임의 구현 및 인터페이스 디자인을 제안한다. 컴퓨터비전 알고리즘을 이용한 본 시스템은 2 차례에 걸친 총 60 명의 사용자들을 통해 기능성과 사용성 면에서 단편적이나 게임 인터랙션 방 식으로의 비접촉 제스처 인식의 가능성을 보여주었다. 이러 한 결과는 기존에 고착화된 스마트 디바이스 게임 인터페이 스에 새로운 방향을 제시하는 계기가 될 수 있겠다. 본 연구
의 장기적인 목표로는 좀 더 많은 제스처의 입력 정보를 사 용하여 보다 더 복잡하고 다양한 인터랙션을 구현하고자 하 며, 게임의 특성인 재미 부분을 사용자가 인지하는지 여부에 대하여 뇌파의 측정이나 신체의 변화 등 좀 더 객관화 된 실험방법을 채택하여 그 근거를 더욱 공고히 하고자 한다.

\section{Acknowledgements}

"This research was supported by the MKE(The Ministry of Knowledge Economy), Korea, under the "IT Consilience Creative Program" support program supervised by the NIPA(National IT Industry Promotion Agency)" (NIPA-2012-H0201-12-1001).

\section{References}

Billon, R., Nédélec, A. and Tisseau, J., "Gesture Recognition in Flow based on PCA Analysis using Multiagent System", In Proceedings of ACE. 2008.

Blain, T., "The convergence of alternate controllers and musical interfaces in interactive entertainment", In Proc. of the 2005 international conf. on new interfaces for musical expression (NIME05), p.27-33, 2005.

Elmezain, M., Al-Hamadi, A., Appenrodt, J. and Michaelis, B., A Hidden Markov Model-Based Continuous Gesture Recognition System for Hand Motion Trajectory. In Proceedings of 19th International Conference on Pattern Recognition, p.1-4, 2008.

He, G. F., Park, J. W., Kang, S. K. and S. K. ung, S. K., "Development of Gesture Recognition-Based 3D Serious Games", Journal of Korea game society, p.103-114, 2011.

Hoysniemi, J., "Design and evaluation of physically interactive games", $\mathrm{PhD}$ thesis, University of Tampere, 2006.

Ju, D. Y., "Contactless gesture-based interaction for smart mobile games.", In Proc. of ESK Spring conf. \& $14^{\text {th }}$ Korea-Japan joint symposium, 2012.

Lee, Y. C., Oh, C. M. and Lee, C. W., "Mobile Game Control Using Gesture Recognition", Journal of the Korea contents association, p.629-638, 2011.

Liu, J., Zhong, L., Wickramasuriya, J. and Vasudevan, V., "uWave: Accelerometer-based personalized gesture recognition and its applications", Pervasive Mob. Comput., 5(6), 657-675, 2009.

Mistry, K. and Zhang, L., "Gesture Recognition Exploration using Haartraining and $\mathrm{KNN}$ in a 3D Racing Game", In proceedings of MIAA. p.37-40, 2011.

Mitra, S. and Acharya, T., "Gesture recognition: A survey. IEEE Trans. Syst.", Man and Cybern., 37(3), 311-324, 2007.

Park, J. Y., Kim, G. C., Park, J. W. and Lee, J. H., "Interactive Boxing Game Based on Computer Vision", Sungkyunkwan University, p.35 
$-51,2005$.

Park, Y. and Kihl, T., "A study for the user interface of rhythm action games on smart device", In Proc. of Korea game society p.191-197, 2011.

Pavlovic, V. I., Sharma, R. and Huang, T. S., "Visual interpretation of hand gestures for human-computer interaction: A review". PAMI, 19(7), 677-695, 1997.

Westerman, W. C. and Elias, J. G., "System and method for packing multitouch gestures onto a hand", April 2006

Wilson, A. and Shafer, S., "XWand: UI for intelligent spaces". In Proc. SIGCHI conf. Human factors in computer system, pages 545-552, 2003.

Wobbrock, J. O., Wilson, A. D. and Li, Y., "Gestures without libraries, toolkits or training: a $\$ 1$ recognizer for user interface prototypes", In Proc. ACM UIST, pages 159-168, 2007.

Yang, M. H., Ahuja, N. and Tabb, M., "Extraction of 2D motion trajectories and its application to hand gesture recognition", IEEE Trans. Pattern Anal. Mach. Intell., 24(8), 1061-1074, 2002.

Yuk, H., "A study on the types of interactive motions in mobile touch interface", $\mathrm{PhD}$ thesis, Hongik University, 2009

\section{Author listings}

Da Young Ju: dyju@yonsei.ac.kr

Highest degree: $\mathrm{PhD}$, Department of Media Technology, School of Media, Sogang University

Position title: Assistant Professor, Yonsei Institute of Convergence Technology, Yonsei University

Areas of interest: HCI, Service Design, Screen-based Interaction, Smart Mobile Interface Design

Date Received : 2012-07-20

Date Revised :2012-07-31

Date Accepted : 2012-08-01 